\title{
Simple and elegant--The aesthetic of Mi Fu's cursive script
}

\author{
Yipeng Luan
}

School of Fine Arts, Weinan Normal University, Weinan Shaanxi, 714000, China

Key words: Mi Fu, Simple and elegant, Cursive script, Natural and drifting, Revelation.

\begin{abstract}
Mi Fu's aesthetic view on cursive script is very clear, that is, simple and elegant. Simple and elegant precisely requires a kind of natural and drifting quality as ancient people. This has created his unique small cursive script which seems contradictory with his running script creation, but the fact is that this aesthetic promoted the maturity and subsequent development of his running script style. The aesthetic of simple and elegant has a great significance on being able to see massive ruins of ancient calligraphy today.
\end{abstract}

\section{Introduction}

Most theorists agree that the achievement of Mi Fu's cursive script is not high, besides attributing which to his setting up a "treasure Jin" rope for himself. As for his cursing wild cursive of Zhang Xu and Huai Su and his views on cursive script, mainstream theorists more tent to think that it is because of his habitually speaking astonishing words or there is a deviation--"going out of way" on his understanding on the cursive script.

I think, for this, it is can not be simply judged as right and wrong, or with the conclusion, the cause and effect, far-reaching among which deserve our pondering.

\section{Mi Fu's simple and elegant aesthetic}

Following let's see his major discusses on the simple and elegant aesthetic cursive script

"If the cursive script could not introduce the style of people in Jin, then it would turn out to be something inferior. Dust man Zhang Dian changed the ancient method, astonishing the ordinary person, should be known by someone. Huaisu has some what insipid, when slightly natural, while compressed by the age, not being able to be simple and elegant..."

"...Zhang Dian has the same crime as Liu Po who preached the dust man to create disorder. Huai Su the Southern minority inferior thoroughly understood the reason, only tend to be insipid like blind doctor...before the two Wangs, there was simple and elegant, wanting to buy while lack of enough money..."

"...and there's also no Suo Jing's authentic work provided for us to the place of putting the pen, Yue Yi not well, afraid of being written by others, only people of Tang Dynasty, no ancient style as people of Jin Kingdom."

"Somebody who has collected script like seal characters, looked back that the Wang Xizhi and Wang Xianzhi seemed to own the dirty feelings, that was Emperor Jinwu's script. Xie Yi's quenching script was natural and reverent, Xie An's script was clear and bold, and both of them were suitable for teaching and respecting. Looking back to Wang Xizhi, whose script was vulgar and looked charming. He will not be inspired by the stone drums alone but wanted to see such things also."

Emperor Wu's script was haltered and damaged but the ink color was still new. The place where there was ink was not damaged. Sign, can anyone's temporary ability make people quit pen and start researching? If ancient people obtained scripts like this, they will realize a higher level and get to a 
new situation. If they only study the books and collections of people in Tang Dynasty, the temper and dispositions are awkward and weak, there will be any reason to win? The meaning and scene are like the people in Tai Koo, it is natural to own the quality of wild and impulsive, Zhang Xu and Huai Su can even reach the hedge?

$\mathrm{Mi} \mathrm{Fu}$ has expressed his ideas on aesthetic of cursive scripts. All above are not all his ideas but his core viewpoints can be seen from these clearly. The viewpoint can be indicated as: he liked the elegant and antique feelings before Wang Xizhi and Wang Xianzhi. His "precious Jin" mainly refers to precious Western Jin Dynasty. Even in East Jin Dynasty, he just liked those works close to elegant and antique style except for Wang Xizhi and Wang Xianzhi. For example, he has mentioned the event for many times that Xie An once commented Wang Xianzhi's script by tiewei. It was about that Wang Xianzhi spoke highly about this calligraphy and wrote to Xie An thinking that Xie An would treat his script as treasure and collected his calligraphy but he never thought about that Xie an replied at the end of Wang Xianzhi's letter and sent back the letter together. Wang Xianzhi was humiliated a lot by this. Centuries later when Mi Fu has saw Xie An's authentic work and worshipped a lot, and then commented as "Qingmai" and above Zijing in the style. He thought it reasonable that Xie An criticized Wang Xianzhi's calligraphy.

Through Mi Fu's comments on cursive scripts, I summarize as follows: Mi Fu's mainly understand the unadorned and antique style in below aspects: 1 . With antique sense; 2 . Not only simple; 3. Like sealed script; 4. Natural; 5. Clear and bold; 6. Like people from Tai Koo with the character of wild. The sixth point can be the punchline pointing out the essence of being unadorned and antique. Being natural and wild is the spiritual core of being unadorned and antique. The words come from Mi Fu's "Script of Emperor Wu" in "Qunyutang Fatie". Some people regarded Fu as Chun. But it could be more like fu from cursive writing which means floating and sparse. It is suitable to be used here. The wild should refer to being substantial, plain and simple. Fuye means to be unadorned and simple that people desired. The sparse and remote scene is just like people from Tai Koo. This kind of aesthetic ideal is obviously originated from Lao-Zhuang philosophy. The eightieth chapter of "Laozi" describes how to go back to Tai Koo society, "a small country with a small population with sharp weapons, and boats, people never use; there are soldiers in arm, there are no place to lay out, so people use by repeatedly knotting". "Zhuangzi Quqie" said hat, "disturbing various music and destroy each instrument, stuff those blind musicians to make people maintain the acute hearing sense". Laozi and Zhuangzi's words are exaggerate and resentful, the major meaning is clear, to quit all diabolic tricks and wicked craft to recover the native and simplest living condition. The extremely antique idea of Laozi and Zhuangzi can never be realized in reality, but the pursuit of simplicity from spiritual level are deeply rooted in scholars' mind and usually reflected in their artistic vies. Mi Fu, the scholar of Song dynasty can be regarded as one of the official heir of Lao-Zhuang philosophy and ideology.

For the realm of being unadorned and antique, poetics have mentioned a lot. For example, Si Kongtu once said in the chapter of "unadorned and antique" in his work "The Twenty-four Poetic Styles", "grotesques ride on air with lotus in hand, expanse like great calamity and vanished remote and obscure, the moon appeared in the east with wind blue sky. People heard of the clock standing in the plain and remote place. There remained only Huangtang and Xuanzong". It depicted the spacious and profound realm of far from world, remote from human society without restrains. There are many similarities with the unadorned and antique style in Mi Fu's mind, such as nature oriented, different with prevalent custom and detached from the human world. But the unadorned and antique style in Mi Fu's mind pays more attention to the sparse and wild feeling forms in nature and floats with lofty sense.

Regarding the issue of "antique" in calligraphy, people before Mi Fu have made a lot of statements. For example, Yu He, the calligrapher in Southern Song Dynasty once said in his "Theory of Shubiao" that, "antique character is beautiful now, very common; it is human nature to love beauty and dislike nature." [1] Su Guoting once mentioned the merits and demerits of Zhong, Zhang, and father and son of Wang in the Theories on Calligraphy, the critics say that, the four wise men are extraordinary in the history, but today is not like the ancient time. Nature was in the ancient time and nowadays focuses on 
beauty. Nature will be prosperous in generations but it gets vulgar easily due to too beautiful. Although it is better to record words for calligraphy, purity and nature changes all the time with the natured scripts. It is natural to reform. There is no disadvantages in ancient time when the time was not good. The so-called gentleman should never live in the hole with chariot jades in the vertebra?" [2]

Both have mentioned the viewpoint, antique equals to nature which has two levels of meaning, one is substantial in contents and another is simple and plain. Actually both are integral, one from inside and another from the exterior in two different angles. They both mean that one thing is rich inside without splendid superficial decorations outside. Ordinary people like magnificence, called "beautiful", so the more beautiful things are more popular in the later time. It gets vulgar due to too much emphasis on beauty. Calligraphers in Tang dynasty have not opposed vulgar in large scale, and it seemed not a big deal between elegant and vulgar. They only stressed good or bad. But it became a big issue in Song dynasty. Huang Tingjian said, real man can do nothing but vulgar, and cannot be saved once being vulgar. From this perspective, Mi Fu's desire for antique is not a problem being returning back to ancient in general but the desire for antique natured calligraphy which belongs to the aesthetic category as Mi Fu's declaration against vulgar.

"The natural and wild disposition " is a realm he desired, thus his resentment for Wang Xizhi and Wang Xianzhi is not the pretentious words but feelings from his heart based on his aesthetic ideal. So it is natural that he loved so much the calligraphy of Wang Rishi in his earlier time.

\section{The influence of unadorned and antique style on Mi Fu's calligraphy creation}

It is well known that the highest achievement of Mi Fu's calligraphy is the cursive which also followed the example of Wang Xizhi and Wang Xianzhi. It seems to form huge contradiction with Mi Fu's resent for both two people. "Looking back, Wang Xizhi and Wang Xianzhi seemed to own the dirty feelings". Looking back to Wang Xizhi, whose script was vulgar and looked charming. He will not be inspired by the stone drums alone but wanted to see such things also." "There is unadorned and antique style in Wang Xizhi and Wang Xianzhi's calligraphy earlier", but he also said amazing words in his later years, "to clear out the evil in Wang Xizhi and Wang Xianzhi to shine the Song dynasty forever". It cannot be denied that Mi Fu has the habit to pretend saying amazing words, we cannot say that he say from his heart to express the meaning in some level too much. Nobody but Mi Fu can feel the benefits of Wang Xizhi and Wang Xianzhi. But he knew more clear that he will get himself lost if blindly learn from them and he could never be one of them.

$\mathrm{Mi} \mathrm{Fu}$ called himself to collect the ancient scripts and followed many masters as teachers. He firstly followed Tang people as teacher, and followed Su Shi's advice at his 32 to learn from Jin people majoring in Wang Xizhi and Wang Xianzhi. In his 33 years' old, he has owned the style of Wang's writing in his script "Fangyuan Anji" which was romantic and dissolute with great eloquence. In his 36 years' old, he obtained the "Script of Xie An" and thought it better than Wang Xianzhi. In the second year of Yuanyou, he saw the thirteen scripts of Jin scholars at Senior Grand Tutor Li Wei, and was extremely shocked. He experienced the beauty of unadorned and antique style as mentioned in above article.

In the second year of Yuanyou, Mi Fu at his 37 years' old has experience the big moment in his life to see the thirteen scripts of Jin scholars. It seems like to be significant from the calligraphy collection and he wanted to spend all his money to buy all, "I can't buy even spending all money and want to cry when I come back". Then he could not forget, and finally bought all of them in the second year of Jianzhong Jingguo after 15 years to realize one of his life dream. The more important significance was in artistic creation. Although he was upset of suddenly losing, he could never go back after seeing all just as what Gao Juhan said. In the next year, he created two masterpieces "Poets scripts of Shaoxi Creek" and "Shu Su Tie", which was quiet and natural, even better than his previous works. The unadorned and antique style was indirectly reflected in both same like Wang Xizhi and Wang Xianzhi's works. At that time, his own style was established. After possessing the thirteen scripts of Jin scholars, his cursive scripts presented more and more unadorned and antique style, from "Ganlu 
Tie", "Poems of Hongxian County", "Poems of Duojing pavilion", and "Poqiang Tieba", etc., unadorned and antique style can be clearly seen. Thus I don't agree with the statement that the vacuity after seeing the the thirteen scripts of Jin scholars is a confused period of his artistic career, but I think it was a turning point. What he has felt in cursive scripts may not absolutely be realized in cursive calligraphy. Mi Fu's cursive benefits from the unadorned and antique style that he has obtained from the cursive scripts of Jin people.

Let's see more cursive creations of Mi Fu's that many people thought not successful. Mi Fu liked the wild cursive of Zhang Xu and Huai Su in his youth, and he also praised, "people love Zhang Xu's works madly, I like Huai Su' directly to the heaven, the stroke can roll up the water in the Three Gorges, and the ink can render them into springs and deep valleys." [3]

It seems that young $\mathrm{Mi} \mathrm{Fu}$, energetic, high-spirited and vigorous, was shocked by the bewildering majestic momentum reflected in the wild cursive of Zhang Xu and Huai Su, and highly praised from the heart. The heroic spirit pressing forward with indomitable will in his calligraphy creation like horse running and blasting wind, quick swords in the battlefields must have been influenced by the wild cursive calligraphy. Later when he saw the cursive scripts of Jin people, he worshipped the unadorned and antique style, then completely quit the wild cursive and scolded Zhang Xu as wide and odd, thought Huai Su as plain. The turning was sudden for people in hundreds of years later but a natural choice after long-time creation deposition for $\mathrm{Mi} \mathrm{Fu}$. This is related with the persuasion from Su Shi to learn from Jin people, the overall aesthetic ideal in Northern Song dynasty, and the idea when he finally realized his desired realm after he has seen the authentic works of Jin people's cursive scripts. Abandoning cursive scripts never shows his shallow understanding of cursive scripts but means that he has made suitable choice based on his own aesthetic ideal.

The only regretful may be that he has seen too few cursive scripts from Jin people, let alone those authentic works before Jin dynasty so that he could not obtain broadly and absorb profoundly to cast his own bright style. But anyway, because Mi Fu has made outstanding achievements in cursive scripts, we require too strictly on his cursive scripts. Actually, as far as the attainment of calligraphy, nobody can rival with Mi Fu in the small cursive script about the unadorned and antique style of Jin people. The natural, natural and unrestrained stroke, compact and thick and solemn structure, easy and free layout, and the most wonderful is the boundless, unadorned and antique style reflected among the natural and unconventional feelings. To make a fair judgement, Mi Fu merits the reward of champion in cursive script in Song dynasty.

\section{The enlightening significance of Mi Fu's unadorned and antique aesthetics and cursive script creation}

Although cursive scripts in two Jin dynasties $\mathrm{Mi} \mathrm{Fu}$ has seen have not existed, thanks to the development of modern archaeology, we can see huge amount of calligraphy work before Wang Xizhi now. Bamboo and wooden slips in Qin and Han dynasties, remained papers in Loulan, Buddhist scriptures of Dunhuang Mss. Cursive scripts exist a lot in bamboo slips and paper books in extremely broad time range. "Biography of Shenwu" unearthed from Yin wany Han tomb is a work from Western Han dynasty that Mi Fu never dreamed of at that time.

Although few relics of cursive scripts in the two Han dynasties and Jin dynasties are famous master pieces, they are authentic works. Besides, some are in high level of calligraphy skill. For instance, the "Script of May third" can rival with Wang Xizhi's work. The turning of spearhead in the authentic works are obviously what the copies in the late generations can match. Compared with people who learned calligraphy basically depending on books of rubbings since Song dynasty, today's condition is very luxurious.

The cursive scripts in two Jin dynasties making Mi Fu feel the unadorned and antique beauty seem not rare in front of mass of earlier relics of scripts as the quality of natural and wild style is everywhere. The only imperfect thing is nowadays people's ability of sense. We can assume that if the cursive scripts making Mi Fu inspired a lot are presented in front of the public today, nothing but their huge economic value can stimulate the great waves in the calligraphy circle. 
I am not meaning to stress the passion for unadorned and antique style by following $\mathrm{Mi}$ Fu but meaning that nowadays calligraphy has been far away from the infection and appealing directly to people's mind so that people has lost their sensibility to feel the spirit in calligraphy.

Today the least of all that we lack is the ability of copycat and imitation of the appearance and faking antiques. Calligraphy should major in use of brush. Mi Fu called for that the first thing of calligraphy is to obtain the brush, this the cursive script of writing the style of poets from Jin Kingdom never pretended the intentional look for the sake of being unadorned and antique. The unadorned and antique style lies in the connotation and mind rather than depicting the appearance and pretending to be profound.

Unadorned and antique is a timeless topic which actually accords with human nature's inclination of pursuing nature and returning to simplicity. It is not only about the artistic style. It can be seen to go to the right place to understand the unadorned and antique style $\mathrm{Mi} \mathrm{Fu}$ has yearned if we understand from this level, which has a significance never out of date for us today.

\section{Reference}

[1] Yu He, Theory of Shubiao, Collected papers of calligraphy in previous generation, Shanghai, Shanghai Book and Painting Press, 1979:50.

[2] Sun Guoting, Theories on Calligraphy, Collected papers of calligraphy in previous generation, Shanghai, Shanghai Book and Painting Press, 1979:124.

[3] Wo Xinghua, Studies on Mi Fu's Calligraphy, Shanghai, Shanghai Chinese Classics Publishing House, 2006:22. 